\title{
Children and adolescents born very preterm do not adapt their planning time after having made an error
}

\section{Vera Disselhoff ${ }^{1,2}$, Barbara Schnider ${ }^{1,2}$, Bea Latal ${ }^{2,3}$, Cornelia Hagmann ${ }^{1,2}$, Flavia Wehrle ${ }^{1,2,3}$}

'Department of Pediatric and Neonatal Intensive Care, University Children's Hospital Zurich, Switzerland; ${ }^{2}$ Children's Research Center, University Children's Hospital Zurich, Switzerland; ${ }^{3}$ Child Development Center, University Children's Hospital Zurich, Switzerland

\section{Background}

- Very preterm birth is birth $<32$ weeks of gestational age

- Among other deficits ${ }^{[1-3]}$, children and adolescents born very preterm (VPT) frequently show impaired planning abilities ${ }^{[4,5]}$, particularly if the demands placed on their planning abilities are high

- Both planning performance and planning time have been shown to be altered in VPT compared to term-born (TB) children $[2,7]$

- Poor planning abilities are associated with impaired problem solving and may hinder successful adjustment in complex environments (e.g., secondary school) ${ }^{[5,6]}$

\section{Methods}

Sample description

\begin{tabular}{|r|r|r|}
\hline & VPT $(n=41)$ & TB $(n=43)$ \\
\hline Sex & 23 boys / 18 girls & 21 boys $/ 22$ girls \\
\hline Age (at assessment) & $12.9 \pm 1.7$ years & $13.1 \pm 2.0$ years \\
\hline GA (in weeks) & $29.6( \pm 2.1)$ & $\geq 37$ \\
\hline IQ (at assessment) & $105.5( \pm 7.0)$ & $109.5( \pm 6.8)$ \\
\hline
\end{tabular}

Mean ( \pm 1 Standard Deviation). ${ }^{*} p=0.02$

\section{Assessment of planning abilities}

- Stockings of Cambridge (SOC)

- Computerized subtest of the CANTAB (see Fig. 1)

- Task: Set of 3 colored balls should be matched to specified pattern in minimum number of moves (see Fig. 2)

- Task difficulty is manipulated by increasing the number of moves needed (2-, 3-, 4- and 5-move problems)

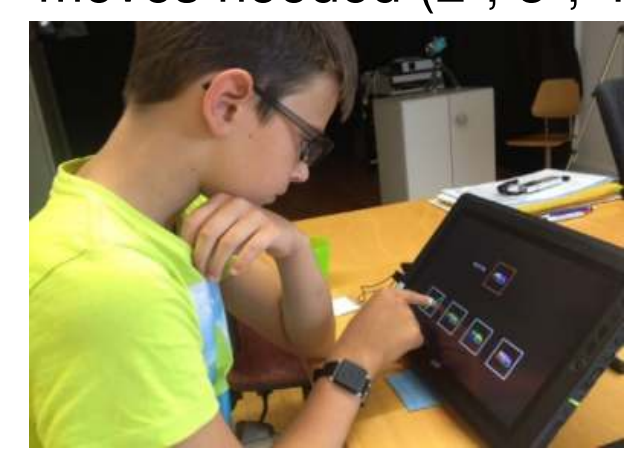

Figure 1. Realisation CANTAB.

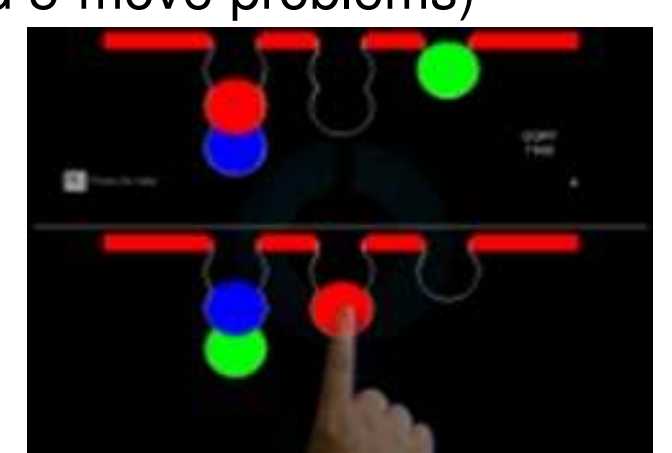

Figure 2. Stockings of Cambridge (SOC).

- Outcome measures

- Time from start of the task to time of the first move $=$ planning time

- Number of moves performed exceeding number of minimal moves required to solve task = planning errors

- Relative error rate change $=\frac{\Delta \text { Errors level } 1 \text { to } 4}{\text { Errors level } 1}$

- Relative planning time change $=\frac{\Delta \text { Planning time level } 1 \text { to } 4}{\text { Plang }}$

\section{References}

${ }^{1}$ Burnett et al., $2018{ }^{2}$ Loe et al., 2012

${ }^{3}$ Burnett et al., $2015{ }^{4}$ Anderson, 2002

${ }^{5}$ Haebich et al., $2017^{6}$ Luu et al., 2011

${ }^{7}$ Wehrle et al., 2016

\section{funded by}

Anna Mueller Grocholski-Stiftung

Gottfried und Julia Bangerter-Rhyner-Stiftung

Hartmann Müller-Stiftung

Uniscientia Stiftung
Aim

Investigate whether insufficient planning time underlies poor planning performance in highly demanding tasks in very preterm born children and adolescents.

\section{Summary}

- Across groups, those participants whose planning performance decreases the most across increasing task demand levels are the ones who increase their planning time the least.

- VPT participants do not adapt their planning time after having made an error.

\section{Conclusion}

- Impaired adaption of planning time to increasing task difficulty and to their previous performance may underlie VPT participants' problems in complex planning tasks.

- Planning time could serve as a target for interventional approaches.

\section{Results}

- Across all participants: Higher error rate change was related to lower change in planning time $(r=-.325, p=.003$; see Fig. 3).

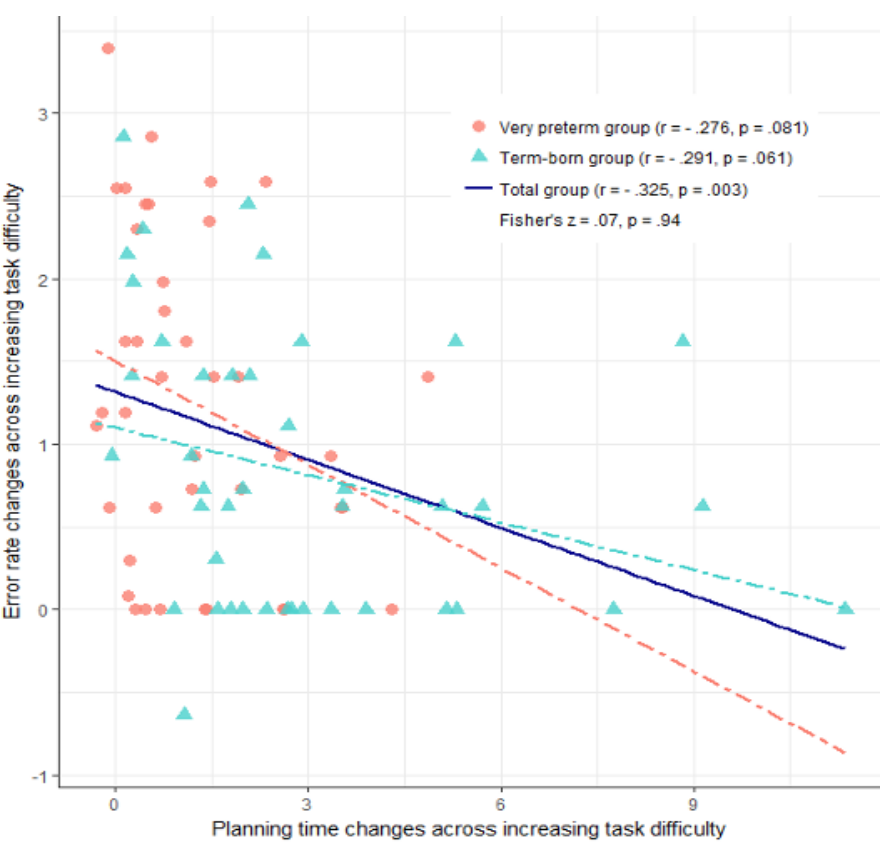

Figure 3. Higher error rate change correlates with planning time change.

Unlike TB participants, VPT participants did not increase their planning time after having made an error in the highest task-difficulty level (interaction birth status $\mathrm{x}$ time-point: $F=$ 4.857, $p=.032$; see Fig. 4).

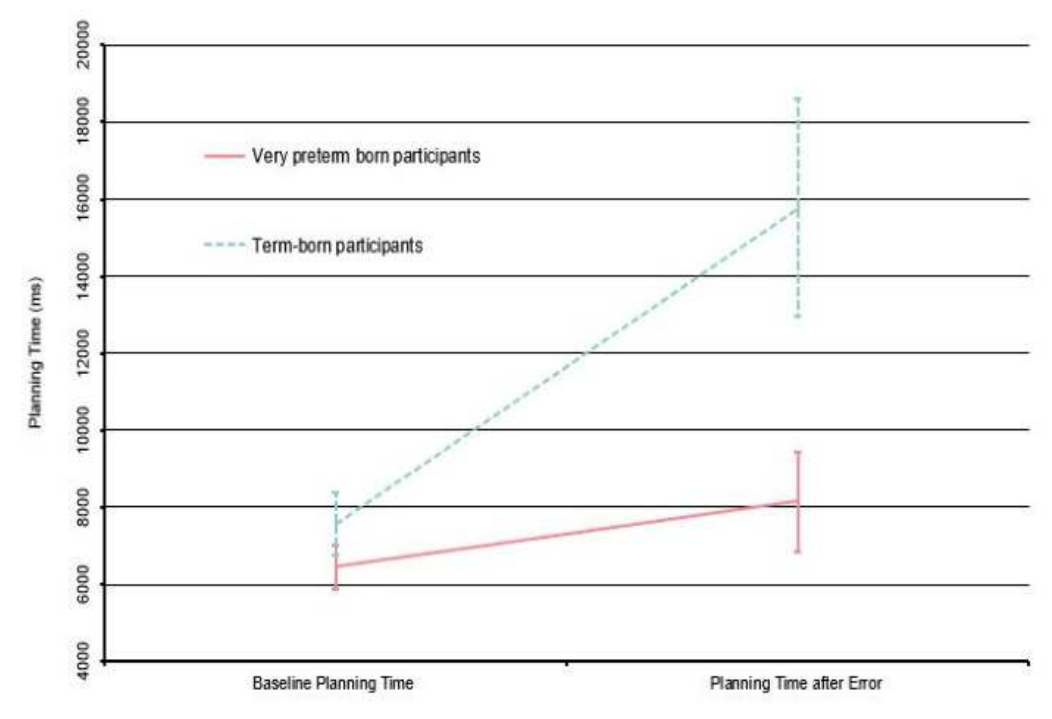

Figure 4. No increased planning time in VPT participants after error. Error bars reflect \pm 1 standard error. 